UNITED STATES ATOMIC ENERGY COMMISSION

\title{
THE CLADDING OF ZIRCONIUM
}

By

H. A. Saller

J. R. Keeler

E. R. Szumachowski

December 20, 1951

Battelle Memorial Institute

Columbus, Ohio

Technical Information Service, Oak Ridge, Tennessee 


\section{DISCLAIMER}

This report was prepared as an account of work sponsored by an agency of the United States Government. Neither the United States Government nor any agency Thereof, nor any of their employees, makes any warranty, express or implied, or assumes any legal liability or responsibility for the accuracy, completeness, or usefulness of any information, apparatus, product, or process disclosed, or represents that its use would not infringe privately owned rights. Reference herein to any specific commercial product, process, or service by trade name, trademark, manufacturer, or otherwise does not necessarily constitute or imply its endorsement, recommendation, or favoring by the United States Government or any agency thereof. The views and opinions of authors expressed herein do not necessarily state or reflect those of the United States Government or any agency thereof. 


\section{DISCLAIMER}

Portions of this document may be illegible in electronic image products. Images are produced from the best available original document. 
Date Declassified: November 9, 1955.

This report was prepared as a scientific account of Government-sponsored work. Neither the United States, nor the Commission, nor any person acting on behalf of the Commission makes any warranty or representation, express or implied, with respect to the accuracy, completeness, or usefulness of the information contained in this report, or that the use of any information, apparatus, method, or process disclosed in this report may not infringe privately owned rights. The Commission assumes no liability with respect to the use of, or from damages resulting from the use of, any information, apparatus, method, or process disclosed in this report.

This report has been reproduced directly from the best available copy.

Issuance of this document does not constitute authority for declassification of classified material of the same or similar content and title by the same authors.

Printed in USA, Price 15 cents. Avallable from the Office of Technical Services, Department of Commerce, WashIngton 25, D. C. 


\section{THE CLADDING OF ZIRCONIUM \\ Prepared by: H. A. Saller \\ J. R. Keeler \\ E. R. Szumachowski}

December 20,1951

\section{ABSTRACT}

Zirconium was roll clad with nickel, monel, inconel, titanium, and an 18-8 stainless steel. With the exception of titanium, all of these metals formed compounds at the zirconium interface and the resulting bonds had poor mechanical properties. The titanium-zirconium bond had good strength and ductility and showed no tendency to crack during thermal cycling.

Sandwich-type diffusion couples of zirconium with copper, molybdenum, platinum, silver, and tantalum indicated that all of these metals formed hard, brittle diffusion products with zirconium.

BAT TELLE MEMORIAL INSTITUTE

$505 \mathrm{King}$ Avenue

Columbus 1, Ohio 
Roll Cladding . . . . . . . . . . . . . 5

Rolling Conditions . . . . . . . . . . . . . 6

Titanium Cladding . . . . . . . . . . . . . 6

Stainless Steel Cladding. . . . . . . . . . . . 9

Nickel Zirconium .. . . . . . . . . . . . 11

Monel and Inconel Cladding . . . . . . . . . . 12

Barrier Metals. . . . . . . . . . . . . 12 


\section{INTRODUCTION}

The roll cladding of thin, protective layers of corrosion-resistant metals to zirconium was investigated as a possible means of utilizing zirconium which has poor corrosion resistance in the Naval reactor. This work was started early in the development program when some doubt existed as to the availability of large quantities of suitably corrosionresistant zirconium.

Metals which were considered to have desirable corrosion resistance were nickel, monel, inconel, titanium, and 18-8 stainless steel, and attempts were made to roll-clad zirconium with each of these metals. The mechanical properties of the resulting bonds were considered to be of primary importance, and, in addition to metallographic examination, the bonds were subjected to bend, chisel, and tensile tests. The stability during thermal cycling was also investigated.

\section{EXPERIMENTAL WORK}

\section{Roll Cladding}

The cladding method consisted essentially in the assembly of cleaned strips of zirconium and the cladding metals in contact in a welded steel sheath. This compact was heated to the desired rolling temperature and rolled with intermediate reheats to the required total reduction.

Machined samples $1-1 / 2$ inches long by $5 / 8$ inch wide were made from each of the metals. The thickness of the strips ranged from 0.080 to 0.140 inch. These samples were assembled, usually a different cladding metal on each side of a central zirconium core, in a mild-steel picture frame. Steel covers $1 / 8$ inch thick were welded to the steel frame by the shielded arc process in an argon filled "dry" box.

A standardized cleaning procedure was adopted for all of the packs. Just prior to assembling and welding the pack, the mating surfaces were abraded with 600-grit paper. The samples were then degreased and cleaned by washing in two acetone and two ether baths. These cleaned strips were assembled in the similarly degreased steel picture frames. Before welding on the steel covers, the inside surface of these covers was coated with magnesia to prevent bonding between the covers and the core. 
Bureau of Mines zirconium was used for all of these studies except those samples which were to be corrosion tested. The corrosion samples were made from arc-melted crystal-bar zirconium. Type-304 stainless steel and commercial-grade nickel, titanium, monel, and inconel were used for the cladding.

\section{$\underline{\text { Rolling Conditions }}$}

The welded packs were rolled in a two-high $8 \times 12$-inch mill at a roll speed of $40 \mathrm{rpm}$. Preliminary experiments indicated that the heating time prior to rolling had little effect on the bonds obtained under otherwise similar conditions. All of the samples were therefore heated 30 minutes before rolling was started. Cross rolling also appeared to have little effect on the character of the bonds and all rolling was done in only one direction.

Rolling temperatures in the range 815 to $1040 \mathrm{C}$ were investigated. With stainless steel, a liquid phase was formed in samples rolled at 1040 C and cladding temperatures for this alloy were limited to $925 \mathrm{C}$. At temperatures of $845 \mathrm{C}$ and below, no bonding was obtained between zirconium and any of the cladding metals. Best results in all cases were obtained between 870 and $925 \mathrm{C}$.

The amount of reduction per pass was varied from ten per cent to 40 per cent and total reductions of from 65 to 85 per cent were investigated. The reheating time between each pass was varied from $1 / 2$ minute to 5 minutes. This variation in the reheating time between passes as well as in the number of passes resulted in total elapsed times from the beginning of the rolling operation to the final pass of from 5 minutes to $1-1 / 2$ hours.

In general, best results were obtained with heavy reductions and short reheating times. Light reductions and long reheating times resulted in extensive diffusion. Brittle diffusion products were formed between zirconium and all of the cladding metals except titanium, and under conditions favorable to extensive diffusion these brittle diffusion bands increased in width and were fragmented during rolling.

\section{Titanium Cladding}

Titanium was the most promising of the cladding materials investigated. Good titanium-zirconium bonds could be obtained over a wide range of temperatures and rolling conditions; in addition, titanium could be bonded to titanium under the same rolling conditions. 
Best results were obtained with 80 per cent total reduction at $925 \mathrm{C}$. Figures 1 and 2 show the bond obtained under these conditions. This sample was reheated two minutes between each pass and the total rolling time was 12 minutes.

Any increase in the total rolling time either because of increased reheating time between passes or because of an increased number of lighter passes resulted in more extensive diffusion.

The mechanical properties of the titanium-zirconium bond were excellent. Sections, $1 / 2$ inch wide, cut from the sandwich could be bent 180 degrees around a 1/4-inch radius and straightened again without cracking the bond. Chisel tests also indicated that this bond had good strength and ductility.

The tensile strength of machined sections of the bond was measured in a jig which permitted a tensile load to be applied to narrow sections of the bond. The tensile strength of four samples averaged 37,200 psi and varied from 33,800 to 40,400 psi.

Sections of the clad sandwich were thermally cycled between 100 and $500 \mathrm{C}$. The samples were sealed in quartz tubes in an argon atmosphere and were cycled by raising and lowering the tubes in and out of a vertical tube furnace. Each cycle required approximately 40 minutes. There was no evidence of cracking after 735 cycles and the test was discontinued.

Several samples of zirconium clad on all sides with titanium were prepared by the picture-frame technique. A titanium picture frame and titanium covers were machined to fit a zirconium core. This assembly was in turn jacketed in a mild-steel jacket which was welded closed in an argonfilled "dry" box. The pack was rolled to 80 per cent total reduction at $925 \mathrm{C}$.

After removing the steel jacket, the titanium sandwich was examined and corrosion tested. There was a concavity in the sheet coinciding with the zirconium core and measurements on cross sections through the core showed that the zirconium had been reduced roughly one per cent more than the titanium covers. In addition, the thickness of the zirconium core was not uniform in the plane parallel with the direction of rolling. Both ends of the core were slightly thicker than the center and the overall thickness of the clad sheet varied in a corresponding manner.

The quality of the zirconium-titanium bond was excellent in all of the sections examined. 


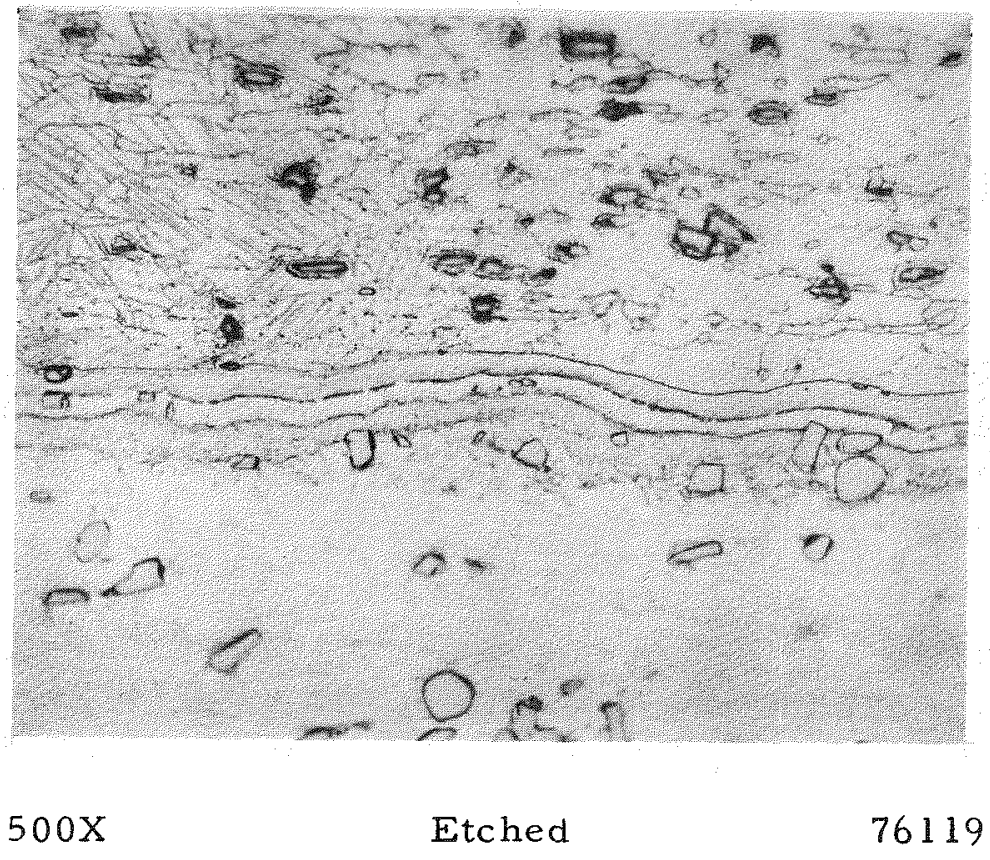

FIGURE 1. TITANIUM-ZIRCONIUM BOND (TITANIUM AT TOP). ROLLED AT $925 \mathrm{C}$ TO 80 PER CENT TOTAL REDUCTION IN 7 EQUAL PASSES

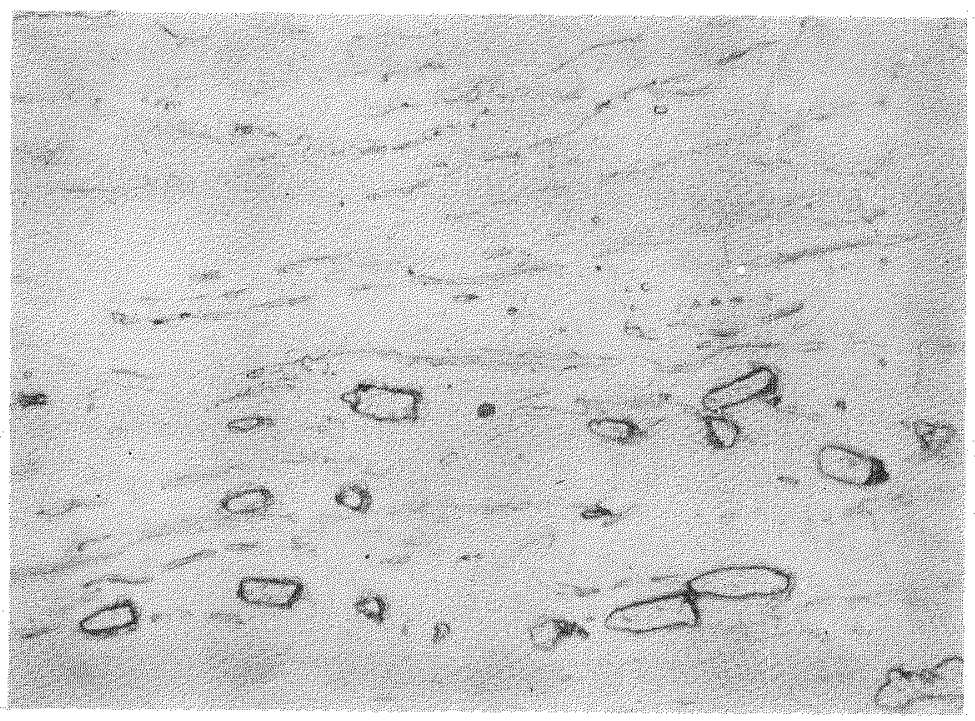


The corrosion resistance of the samples completely clad with titanium was as good as that of the original titanium in $600 \mathrm{~F}$ water. The samples became covered with a dark tarnish film which did not change. There was no preferential attack at the titanium to titanium bond.

Cross sections through the zirconium core were also corrosion tested. These samples were preferentially attacked at the titaniumzirconium bond indicating that although both metals were corrosion resistant, the alloy of the two had poor corrosion resistance.

A sample of zirconium clad on all sides with titanium was machined and sent to Argonne National Laboratory for additional corrosion tests.

\section{Stainless Steel Cladding}

The Type- 304 stainless steel-zirconium bond obtained by rolling these two metals in contact contained a hard, brittle diffusion product which adversely affected the mechanical properties of this bond. Efforts to eliminate or minimize the formation of this brittle phase were unsuccessful. The soundest bonds were obtained by rolling at $925 \mathrm{C}$ with heavy reductions and short reheating times between passes. Figure 3 shows the bond obtained under these conditions. As indicated previously, a liquid phase was observed in samples rolled at $1040 \mathrm{C}$.

Under conditions which permitted more extensive diffusion, the diffusion band increased in thickness and was fragmented during rolling. The resulting bond was weak, and the cladding could be easily stripped from the core.

Sections from bonds similar to that shown in Figure 3 cracked when bent around a 1 -inch radius, and chisel tests also indicated that the bond was brittle. The tensile strength also reflected the brittle character of this bond. The average strength observed on three samples was 18,600 psi, approximately half that observed in the titanium-zirconium bond.

During the thermal cycling of this bond, no cracking was evident after 300 cycles between 100 and $500 \mathrm{C}$, but after 450 cycles, the bond had started to fail. Cycling was continued, and after 620 cycles, severe cracking was evident at the stainless steel-zirconium interface. Other samples which had been roll clad under similar conditions also showed severe cracking in 650 cycles or less. 


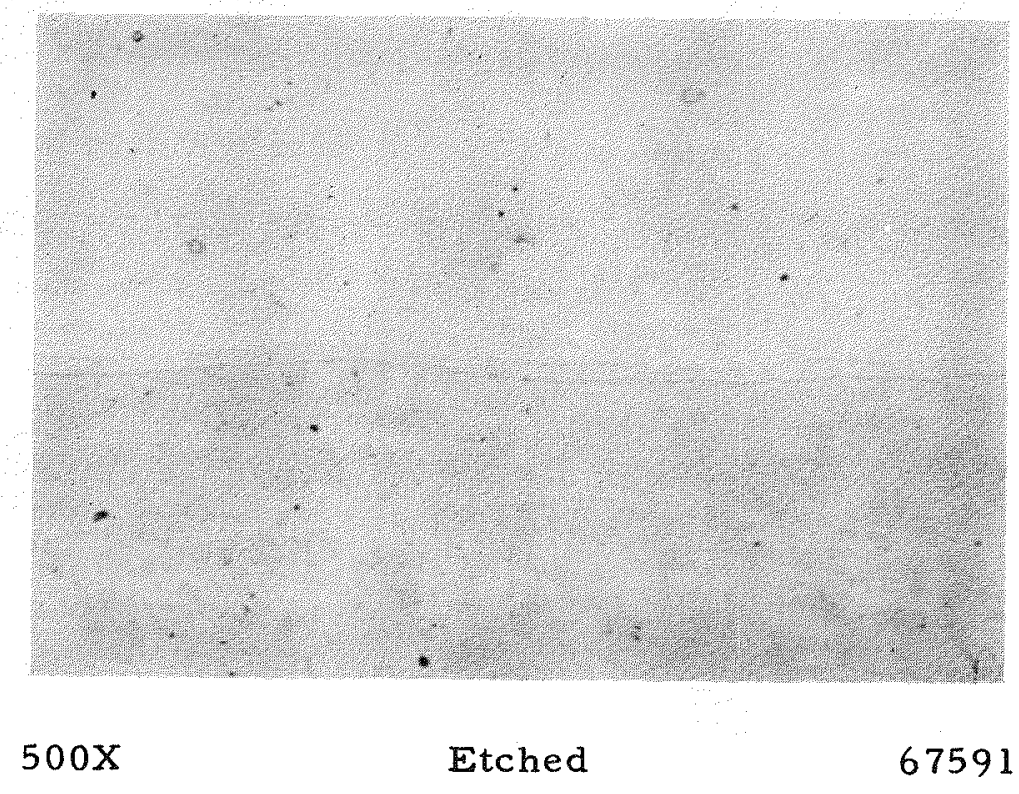

FIGURE 3. STAINLESS STEEL CLAD TO ZIRCONIUM. ROLLED AT 925 C TO 80 PER CENT TOTAL REDUCTION IN 7 EQUAL PASSES. ZIRCONIUM AT BOTTOM

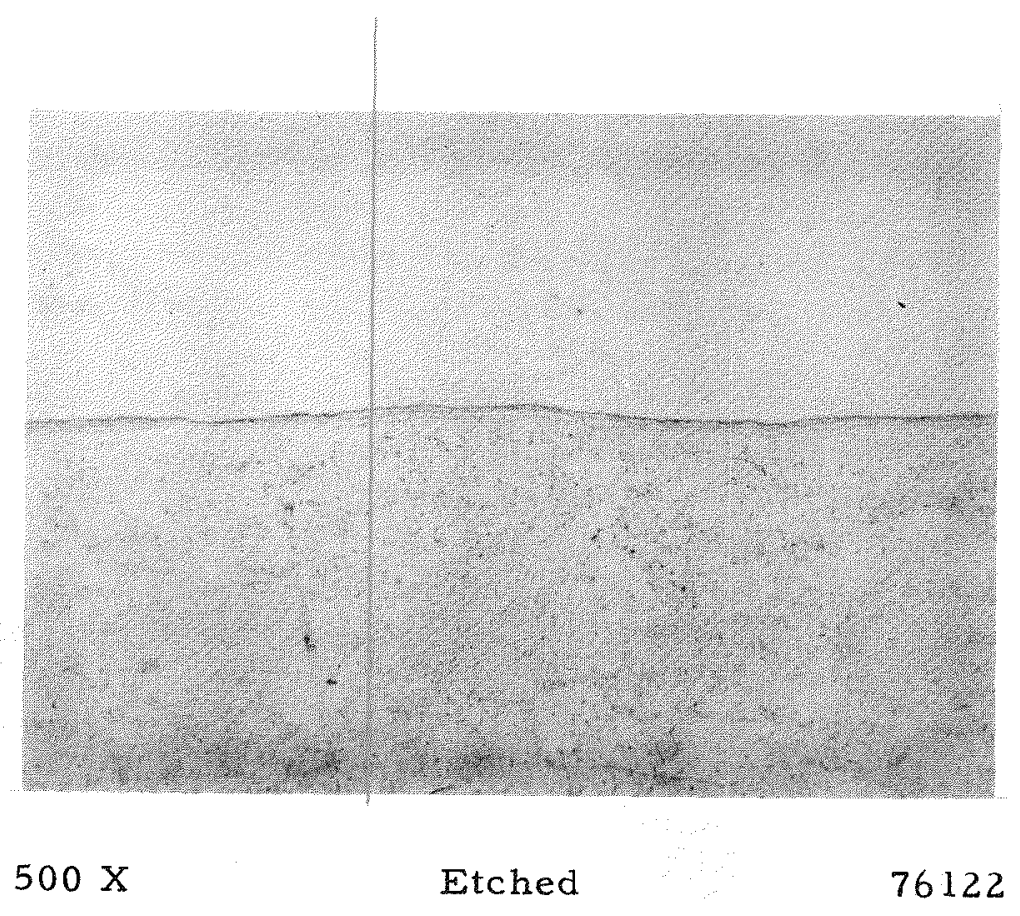

FIGURE 4. NICKEL CLAD TO ZIRCONIUM. ROLLED AT $870 \mathrm{C}$ TO 80 PER CENT TOTAL REDUCTION IN 5 EQUAL PASSES. ZIRCONIUM AT BOTTOM 
Corrosion tests on cross sections through samples of crystal-bar zirconium roll clad with stainless steel showed no evidence of attack after 1000 hours in $600 \mathrm{~F}$ water.

Attempts to clad zirconium on all sides with stainless steel by the picture-frame technique were unsuccessful. The stainless steel failed to bond to itself at the limiting rolling temperature of $925 \mathrm{C}$. In addition, the resistance to deformation or plasticity of the stainless steel and the zirconium differed widely at the rolling temperature. The zirconium was much more plastic than the stainless steel, and as a result was forced toward the ends of the pack and partially out between the cover and frame.

\section{Nickel Zirconium}

The nickel-zirconium bond obtained by roll cladding was also brittle and efforts to improve the mechanical properties of the bond were unsuccessful.

The soundest bonds were obtained by rolling at $870 \mathrm{C}$ with heavy passes (20-25 per cent) and one- to two-minute reheats between passes. Figure 4 shows the structure of the bond obtained under these conditions. Higher rolling temperatures and longer diffusion time resulted in an increase in the width of the compound band formed at the interface and increased the tendency to crack this brittle phase during the rolling operation. Increased diffusion also resulted in the formation of a eutectoid structure in the zirconium adjacent to the interface.

Sections of the bond obtained at $870 \mathrm{C}$ with heavy reductions and short reheating times between passes could be bent 180 degrees around a $1-$ inch radius, and straightened without cracking. Sections could also be bent 180 degrees around a 1/4-inch radius but these samples developed cracks on the bond when the bent section was straightened. Attempts to machine tensile specimens to fit the testing jig were unsuccessful, however; in all cases the specimens cracked at the bond during the machining operation.

The behavior of the bonds during thermal cycling was irratic. A section of a bond, produced under the optimum conditions indicated above, cracked in less than 100 cycles. Other similar bonds had failed after 370 and 640 cycles. 
Monel and Inconel Cladding

The results obtained with monel and inconel were similar to those obtained with stainless steel. Brittle compounds were formed at the zirconium interface with both monel and inconel and both metals failed to self weld at temperatures up to $925 \mathrm{C}$.

Figures 5 and 6 show sound monel and inconel bonds with zirconium.

The tensile strength of the monel bond averaged only 5, $400 \mathrm{psi}$. Sections of this bond could be bent 180 degrees around a 1 -inch radius but the bent sections could not be straightened without cracking the bond. After 150 cycles between 100 and $500 \mathrm{C}$, the bond had started to crack.

The monel bond was so brittle that tensile specimens could not be machined from the roll-clad sandwich and the bond failed when sections of the sandwich were bent 180 degrees around a 1 -inch radius. This bond also failed after 150 thermal cycles between 100 and $500 \mathrm{C}$.

\section{Barrier Metals}

Since zirconium formed brittle compounds with all of the cladding metals except titanium, an effort was made to find a metal which would form ductile bonds with zirconium and also with the cladding metals.

Diffusion couples were made between zirconium and copper, ixon, molybdenum, platinum, silver, tantalum, and cartridge brass. A strip of each metal was placed between two strips of zirconium and this sandwich was clamped together by a welded steel $r$ ing which was plastically deformed around the couple. The mating surfaces of the couple were abraded and cleaned prior to assembly and the samples were heated in a vacuum or an inert atmosphere at temperatures ranging from 825 to $1090 \mathrm{C}$. The heating time was varied from 15 minutes to 5 hours.

The copper-zirconium and iron-zirconium couples showed evidence of fusion when heated to $980 \mathrm{C}$ and the brass-zirconium sample had fused at $900 \mathrm{C}$. Metallographic examination of these samples showed that eutectics had formed and that diffusion of the iron and copper into the zirconium was extensive.

Metallographic examination of the remaining couples showed that in all cases hard, brittle diffusion products were formed at the zirconium interface.

gpo gzzgaz - 2 


\section{$-13-$}

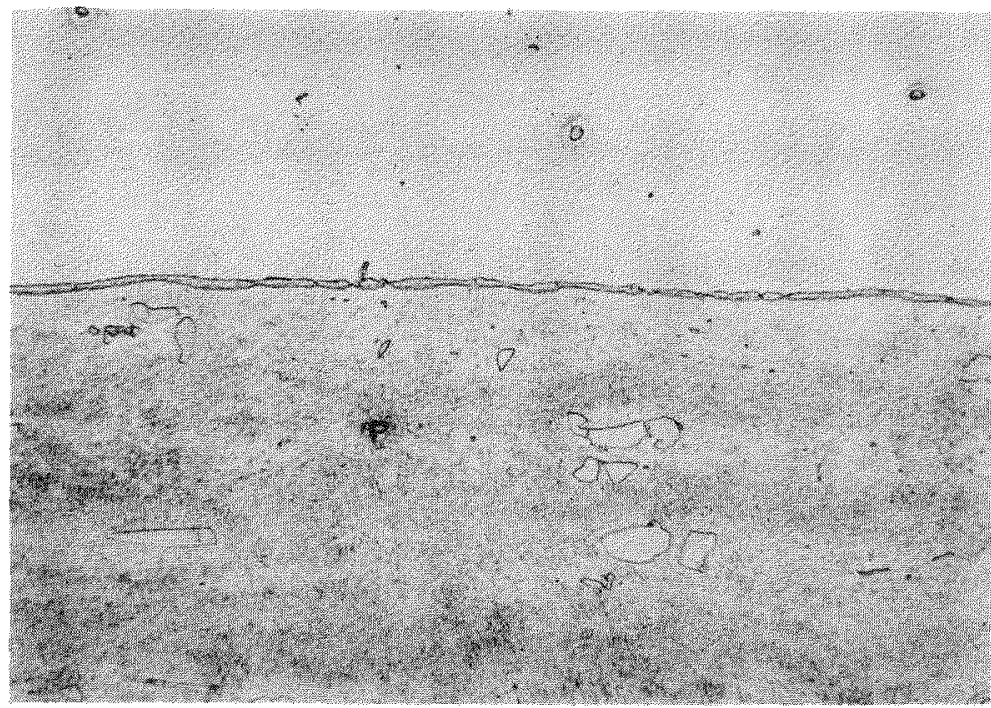

$500 X$

Etched

76120

FIGURE 5. INCONEL CLAD TO ZIRCONIUM. ROLLED AT $870 \mathrm{C}$ TO 80 PER CENT TOTAL REDUCTION IN 7 EQUAL PASSES. ZIRCONIUM AT BOTTOM

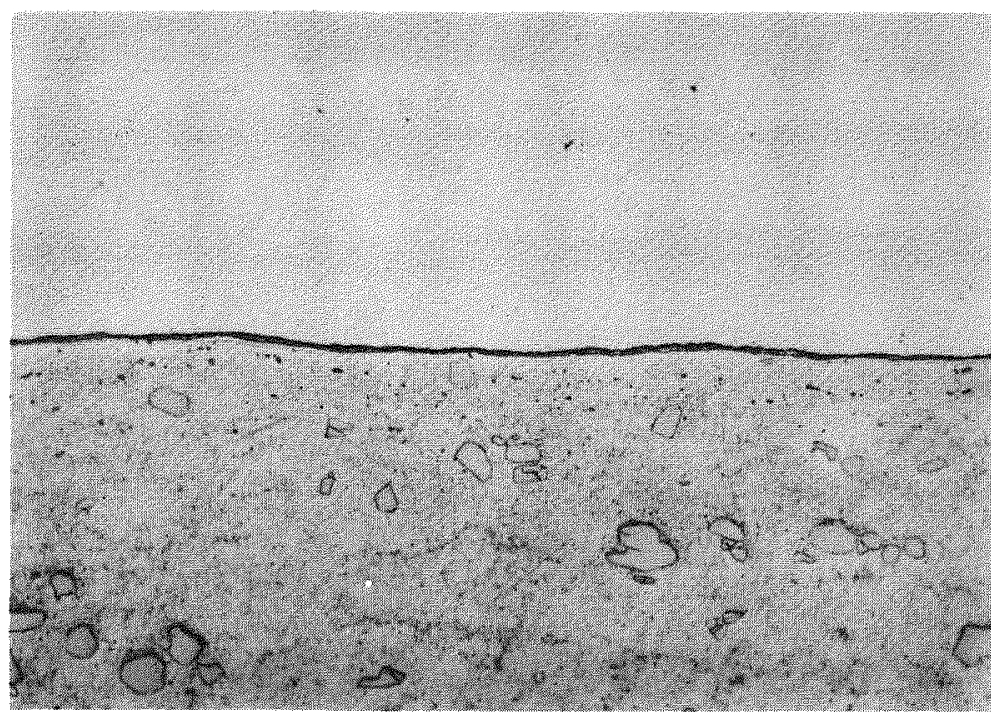

$500 \mathrm{X}$

Etched

76121

FIGURE 6. MONEL CLAD TO ZIRCONIUM. ROLLED AT $870 \mathrm{C}$ TO 80 PER CENT TOTAL REDUCTION IN 7 EQUAL PASSES. ZIRCONIUM AT BOTTOM 